\title{
Topology optimization of a novel fuselage structure in the conceptual design phase
}

\begin{abstract}
Purpose

- In recent years, innovative aircraft designs have been investigated by researchers to address the environmental and economic issues for the purpose of green aviation. To keep air transport competitive and safe, it is necessary to maximize design efficiencies of the aircrafts in terms of weight and cost. The purpose of this paper focuses on the research which has led to the development of a novel lattice-fuselage design of a forward-swept wing aircraft in the conceptual phase by topology optimization technique.

\section{Design/methodology/approach}

- In this paper, the fuselage structure is modelled with two different types of elements -1D beam and 2D shell- for the validation purpose. Then, the finite element analysis coupled with topology optimization is performed to determine the structural layouts indicating the efficient distributed reinforcements. Following that, the optimal fuselage designs are obtained by comparison of the results of $1 \mathrm{D}$ and $2 \mathrm{D}$ models.
\end{abstract}

\section{Findings}

- The topological results reveal the need for horizontal stiffeners to be concentrated near the upper and lower extremities of the fuselage cross section and a lattice pattern of criss-cross stiffeners should be well-placed along the sides of the fuselage and near the regions of window locations. The slight influence of windows on the optimal reinforcement layout is observed. To form clear criss-cross stiffeners, modelling the fuselage with $1 \mathrm{D}$ beam elements is suggested, whereas the less computational time is required for the optimization of the fuselage modelled using 2D shell elements.

\section{Originality/value}

- The authors propose a novel lattice fuselage design in use of topology optimization technique as a powerful design tool. Two types of structural elements are examined in order to obtain the clear reinforcement detailing, which is also in agreement with the design of the DLR (German Aerospace Center) demonstrator. The optimal lattice layout of the stiffeners is distinctive to the conventional semi-monocoque fuselage design and this definitely provides valuable insights into the more efficient utilization of composite materials for novel aircraft designs.

Keywords: Lattice pattern, Composite fuselage, Topology optimization; Conceptual design 


\section{Introduction}

Composite lattice filament-wound tubular structures have been successfully applied for many years by Russian rocket designers due to their excellent strength and stiffness to weight ratios (Vasiliev et al. 2001, 2006). Innovative aircraft designs, like Airbus A350, the integrated airplane layout with new performance synergies (Seitz et al. 2014), and Blended Wing Bodies (Russell et al. 2010), have been investigated to address the environmental and economic considerations for the purpose of green aviation. As metal designs of primary load-bearing structures, for example aircraft fuselages, have reached their climax after 90 years of development in the field of aerospace engineering, it is really challenging to achieve extraordinary weight and cost savings based on the conventional design of commercial aircraft fuselages produced by semi-monocoque construction (Shanygin et al. 2012). To tackle this problem, the potentials of extremely lightweight, high-strength fiber reinforced composites and innovative reinforcement configurations should be further explored in the design of aircraft fuselages. Carbon fibre reinforced plastics have very successful applications in aerospace industries in recent years and they outperform aluminium alloys in terms of very high strength and rigidity (Quilter 2004, Daniel and Ishai 2005). However, the potential of composites has not been completely exploited due to the simple use of conventional aircraft airframe layouts as design principles (Ostrower 2011).

The composite lattice structure was developed and produced by the Russian Central Research Institute for Special Machinery (CRISM) for rocket structures (Wilmes et al. 2002, Herbeck et al. 2003, Kolesnikov and Herbeck 2004, Vasiliev et al. 2012) in the 1980s. These structures consist of ribs either helically or ring-shaped, which are made of unidirectional composite fibres using automatic filament winding. Such structures are known as lattice or anisogrid structures shown in Figure 1. The advanced mechanical properties of the unidirectional composites of the lattice ribs are the main factor to strive for their high weight efficiency, while the skin of the cylindrical or conical shells is usually manufactured to carry an insignificant part of the loading, such as tension, compression and shear. As the automatic filament winding process technique has been well developed to produce composites, an integral structure with a low manufacturing cost is ensured. These achievements open up new opportunities for the optimal design of composite aircraft fuselage barrels (Shanygin et al. 2012, Vasiliev et al. 2012).

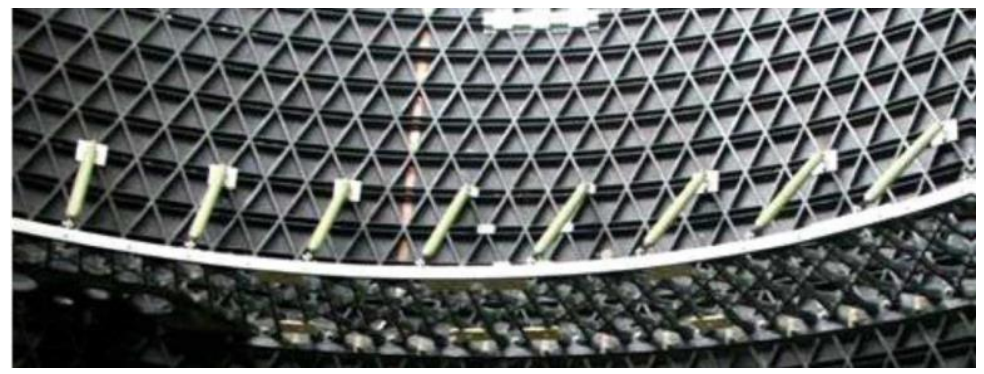

Figure $1 \mathrm{~A}$ barrel in a lattice structure developed for the rocket engineering application

Taking these situations into account, a full-scale load-bearing lattice structure (Wilmes et al. 2002, Herbeck et al. 2003, Vasiliev et al. 2012) was developed as a demonstrator by CRISM and DLR 
(German Aerospace Center) in the field of Rocket Engineering. However, the implementation of composite lattice structures into the commercial aircraft is still an issue. To address this challenging problem, a comprehensive investigation starting with the beneficial geodesic design well-proven in space technology and transferring it to commercial composite aircraft fuselage designs was performed in the project entitled Advanced Lattice Structures for Composite Airframes (ALasCA 2013).

Topology optimization technique (Bendsøe and Sigmund 2003) has been widely used in various engineering disciplines (Zhou 2002, Harzheim and Graf 2005), especially aeronautical and aerospace engineering (Krog et al. 2002 and 2004, James et al. 2014, Rao et al. 2008, Zhou et al. 2010, Zhu et al. 2016). Topology optimization is a finite element based structural optimization process, increasingly used by engineers to support the development of minimum weight structures. With respect to the design objectives, the aim of topology optimization is to identify the most advantageous material distribution inside the design domain. Its methods, theory and various applications have been recently discussed by Deaton and Grandhi (2014).

In this paper, the aircraft configuration and loads applied in the DLR funded project LamAiR (Seitz et al. 2011) are used to model the fuselage of a forward-swept wing aircraft shown in Figure 2 with two different types of elements: 1D beam and 2D shell. Following that, the integration of structural analysis with topology optimization is applied to determine the efficient material layouts indicating the structural reinforcements for the fuselage with and without windows, respectively. Subsequently, the influences of element types and windows on the optimal fuselage design in the conceptual phase are studied. Finally, a lightweight and cost effective lattice fuselage design is practically developed based considering the topological results and manufacturability of the reinforcements.

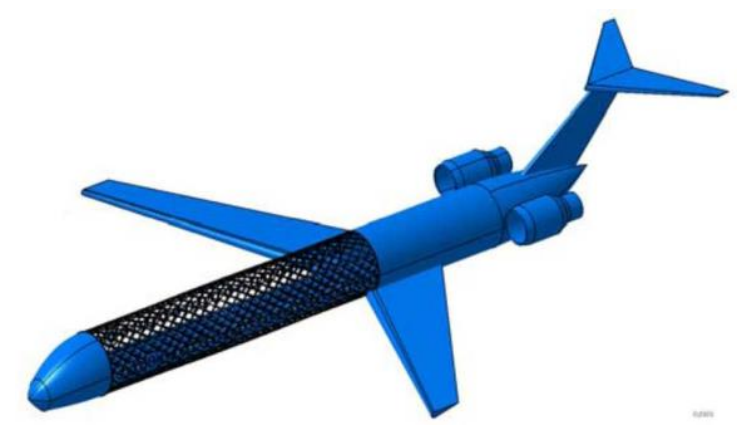

Figure 2 Forward-swept wing aircraft concepts with a long undisturbed lattice fuselage

\section{Topology optimization technique}

Topology optimization is the most general type of structural optimization, being performed in the initial phases of the design. It is a mathematical approach that optimizes the material layout or distribution subject to some constraints in a given design space to achieve the minimum weight 
structures or the most efficient designs. Topology optimization methods for continuum structures seek an optimal material distribution, which defines both the external boundaries of the structure and the number, position, size and shape of internal holes in the structure. In the conventional aircraft fuselage design, the fuselage stiffeners are commonly arranged in the same direction as the axis of the fuselage and are also evenly distributed along its circumference. Such a fuselage is reinforced by longitudinal stringers and constructed by semi-monocoque technique (Airframe 2012), while the utilization of composite materials potentially allows for these stiffeners to be arranged along any axis (Vasiliev et al. 2006, 2012) as well as achieved in a significant reduction in

weight. This is the logic behind why topology optimization technique is proposed in this paper to seek the innovative fuselage design of a forward-swept wing aircraft. In order to provide a scientific basis for finding a rational structural layout for the fuselage design, the Solid Isotropic Material with Penalisation (SIMP) (Bendsøe 1989, Bendsøe and Sigmund 2003, Mlejnek 1992, Sigmund 2001, Zhou and Rozvany 1991) topology optimization method is used to determine the efficient stiffener arrangements.

In a very simple formulation of the topology optimization problem, the artificial material is defined to have a variable material density $q$ and an associated variable stiffness $E(q, q)=q^{q} E$ for each finite element in a design space of the model. Taking $E$ as the stiffness of an isotropic material, a design description that allows each finite element represented by either a void " $\mathrm{q}=0$ " or material " $\mathrm{q}=1$ " is achieved. Using this simple formulation, topology optimization for the design with a minimum total elastic energy $U_{e}$ as the objective function can be simply written as:

$$
\begin{aligned}
& \min { }_{N} U_{e} \\
& \text { subject to } \sum_{\substack{n=1 \\
n=1, \ldots, N}} \rho_{n} V_{n} \leq V_{0} \\
& \rho_{\text {min }} \leq \rho \leq 1
\end{aligned}
$$

where $U_{e}$ is the total elastic energy for the structure; $N$ is the total number of finite elements in the designable area; $n$ is the number of the analysed finite element; $\rho$ is the design variable and artificial element density used by the SIMP method to tailor structural stiffness of each finite element in the structure.

The above provides a classical total elastic energy based topology optimization formulation, which can be also considered as a maximum stiffness or minimum compliance design problem. Normally the buckling requirement is not considered in this stage, but the 'topologically optimized' design should be further fine-tuned afterwards by shape and size optimization methods regarding the stability constraint.

\section{Forward-swept wing aircraft configuration and loads}

In this section, the aircraft configuration from the project LamAiR (Seitz et al. 2011) was used to model the fuselage, cargo and passenger floors, and struts of a forward-swept wing aircraft for structural analysis and topology optimization in use of Altair OptiStruct (2013). The passenger and cargo doors are naturally large cut-outs, which is one of the main features of the forward-swept wing aircraft. These doors are placed in the front cockpit-section and behind the wing, respectively. 
Considering this character, a long undisturbed barrel section can be reasonably defined as the designable part in the optimization process and this would lead to a lightweight and cost-efficient fuselage design.

The length of the fuselage section was $13,652 \mathrm{~mm}$ and it included two introduction bays, each of which was $399.8 \mathrm{~mm}$ in length. The rest of the fuselage had 22 bays and the pitch length between two adjacent bays was $584.2 \mathrm{~mm}$ shown in Figure 3. The cross section was made from three different radii and included a passenger and a cargo floors with struts connecting the floors, see Figure 4.

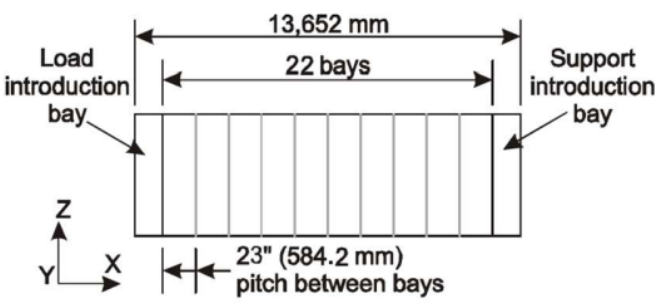

Figure 3 The fuselage configuration

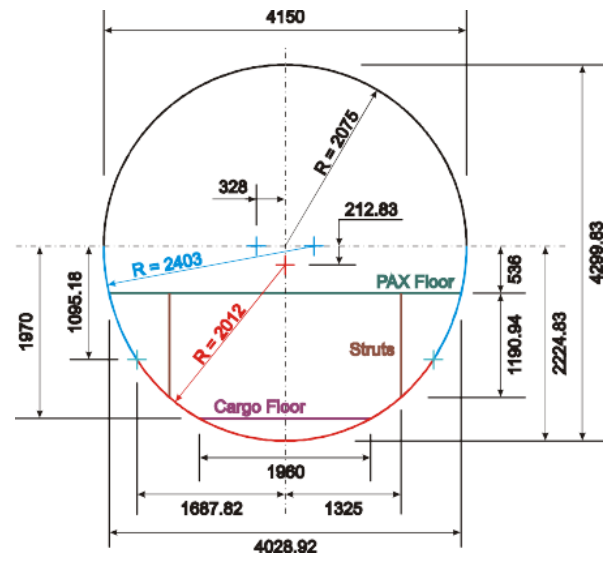

Figure 4 Geometrical parameters

of fuselage cross-section

An upward gust load was applied to the fuselage of the forward-swept wing aircraft flying at low altitude, cruise speed. There were three sources of loads: 1 ) gravitational forces resulting from the uniformly distributed masses on the fuselage and its ring frames, 2) point loads and moments at the free end of the fuselage cross section, and 3) uniformly distributed point loads on the passenger and cargo floors along the fuselage axis. The second group of loads applied the free end was shown in Figure 5 and it included seven concentrated loads, four of which were gravitational forces representing the passenger floor mass and three resulting from the cargo floor mass. The third group of loads was depicted in Figure 6. Based on these loads, three load cases and magnitudes of loads were defined in Table 1 and they were applied on the fuselage to perform the structural analysis and topology optimization. In Load Case 1 (LC 1), there was a load factor of 3.47 acting in the negative z-direction on the mass of the fuselage, ring frames, passenger floor, and cargo floor. A vertical shear force $\mathrm{Q}_{z}$ and moment $\mathrm{M}_{\mathrm{y}}$ were also considered. This retained Load Case

1 a critical load case in the design process. Load Case 2 included a horizontal shear force $Q_{y}$ and a bending moment $\mathrm{M}_{\mathrm{z}}$. Load Case 3 consisted of a torque T about the $\mathrm{x}$-axis applied in either directions.

In the finite element modelling of fuselage section, the fuselage mass was evenly distributed over the entire fuselage elements and this was achieved by assigning the element with the non- 
structural mass property. The ring frames mass in Figure 3 was evenly distributed over the 23 rings. The passenger and cargo floor masses were applied on the fuselage section with the magnitudes $F_{P A X}, F_{\text {Cargo Latches }}$ and $F_{\text {Cargo Central }}$ given by Eqs 2, 3, and 4

$$
\begin{aligned}
& g_{\text {LC }} \times M_{\text {PAX Total }} \\
& \text { PAX } \quad 4 \underset{\times}{F} N_{\text {Frames }}=\square_{i} i \\
& F_{\text {Cargo Central }}=\frac{g_{i L C i}}{} \times M_{\text {Cargo Total }} \\
& 2 \times N_{\text {Frames }} \\
& F_{\text {Cargo Latches }}=\frac{g_{L C_{i}} \times M}{4 \times N} \underset{\text { Frames }}{\text { Cargo Total }}{ }_{i}
\end{aligned}
$$

where:

$$
\begin{aligned}
& F_{P A X_{i}} \quad \text { means point force on passenger floor for } i^{\text {th }} \text { load case } \\
& g_{L G} \quad \text { is the acceleration for } i^{\text {th }} \text { load case } \\
& M_{\text {PAX Total }} \text { represents the total mass acting on the passenger floor for } i^{\text {th }} \text { load case } \\
& N_{\text {Frames }} \quad \text { is the number of ring frames in the model and } 23 \text { (this means } 22 \text { number of } \\
& \text { bays in total) are used in this paper. However, this could vary from the } \\
& \text { number required for a } 508 \mathrm{~mm} \text { to a } 787.4 \mathrm{~mm} \text { pitch length. } \\
& F_{\text {Cargo Central }_{i}} \text { represents the central point force on the cargo floor for } i^{\text {th }} \text { load case } \\
& M_{\text {Cargo Total }} \text { represents the total mass acting on the cargo floor for } i^{\text {th }} \text { load case }
\end{aligned}
$$

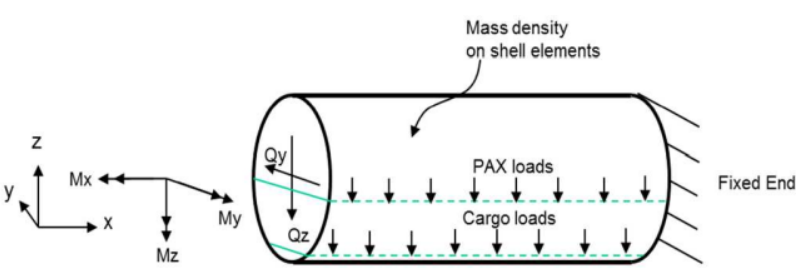


Figure 5 Loads on the passenger and

cargo floors in the plane of fuselage

cross-section

Table 1 Three load cases applied on the fuselage section

\begin{tabular}{|c|c|c|c|c|c|}
\hline Load Case & $\mathrm{Q}_{z}(\mathrm{~N})$ & $\mathrm{M}_{\mathrm{y}}(\mathrm{Nm})$ & $\mathrm{T}\left(\mathrm{M}_{\mathrm{x}}, \mathrm{Nm}\right)$ & $\mathrm{Q}_{\mathrm{y}}(\mathrm{N})$ & $\mathrm{M}_{z}(\mathrm{Nm})$ \\
\hline 1 (downwards loads) & 211,711 & 446,965 & - & - & - \\
\hline 2 (sideways loads) & - & - & - & $\pm 80,000$ & $+249,614$ \\
\hline 3 (torsional load) & - & - & $\pm 280,000$ & - & - \\
\hline
\end{tabular}

\section{Finite Element (FE) modeling and boundary conditions}

The study of fundamental properties of the optimal grid-like pattern in Figure 7 was made by many researchers (Michell 1904, Prager 1974, Rozvany et al. 1993 and 1995, Rozvany 1998). Motivated by Michell's work, intuitive methods of analysing and designing the fuselage structure modelled with 1D beam and 2D shell elements for a maximum stiffness under a given weight are employed in this paper. Since the results obtained by topology optimization can't be applied directly in the practical design process, structural interpretation of topological results using mechanics concepts is given to identify a clear, efficient reinforcement layout for the fuselage of the preceding forwardswept wing aircraft. Also, the influence of windows on the optimal design under the mentioned three load cases in Section Forward-swept wing aircraft configuration and loads are discussed in Section Lattice fuselage design of a forward-swept wing aircraft.

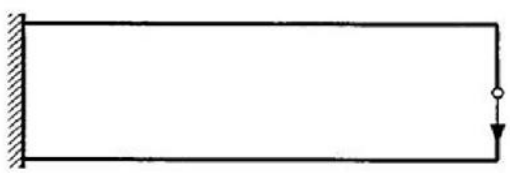

(a)

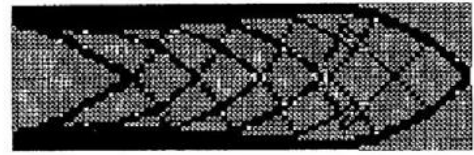

(b)

Figure 7 (a) The Michell cantilever; (b) The generalized shape of a perforated

\section{Fuselage section without cut-outs}

In the detailed FE model of the fuselage without windows shown in Figures 8 and 9, 25584 2D shell 
elements (4-node) and 179088 1D beam element (2-node) were used to construct the fuselage structure, respectively. The passenger floor, cargo floor and struts were modelled with 2254 rod elements (2-node), which only carried the axial forces. The ring frames of the fuselage were modelled with 3588 beam elements (2-node), which bore not only axial forces but out-of-plane forces. The logic behind the structural components being modelled as above was to identify the efficient pattern on the skin of the fuselage tube by assigning loads to the primary load-bearing structures - the reinforcement ribs. At two ends of the fuselage section, there are two introduction bays to reduce the local effects (loading and boundary conditions) on the final results.

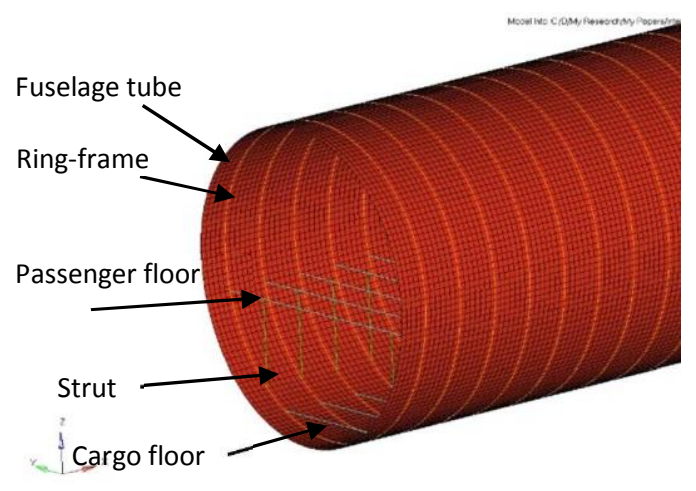

Figure 8 FE modelling of the fuselage tube without windows using shell elments

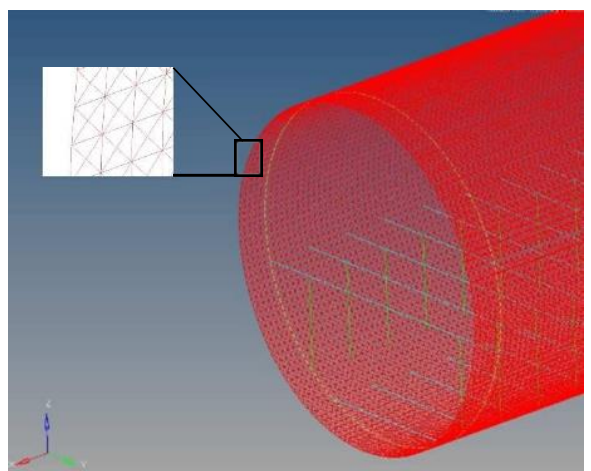

Figure $9 \mathrm{FE}$ modelling of the fuselage tube without windows using beam elments

\section{Fuselage section with cut-outs}

The barrel with cut-outs representing the windows in Figure 10 was modelled with 25100 2D shell elements and $1505801 \mathrm{D}$ beam element, respectively. The pitch length (the distance between two adjacent ring frames) could vary from $508 \mathrm{~mm}$ (minimum distance) to $787.4 \mathrm{~mm}$ (maximum distance). In this study, the frame pitch length of $584.2 \mathrm{~mm}$ was evaluated and the detailed information about window geometry was described in Figure 11.

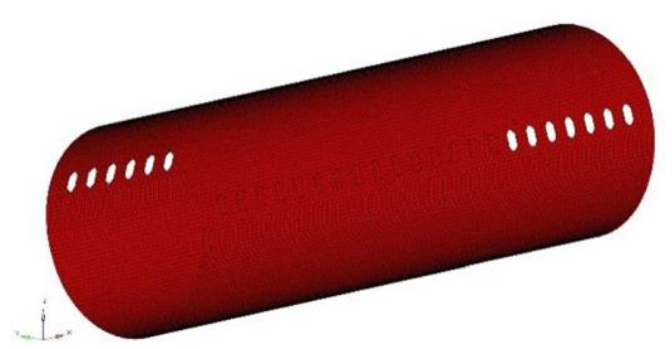

Figure 10 The fuselage with windows 

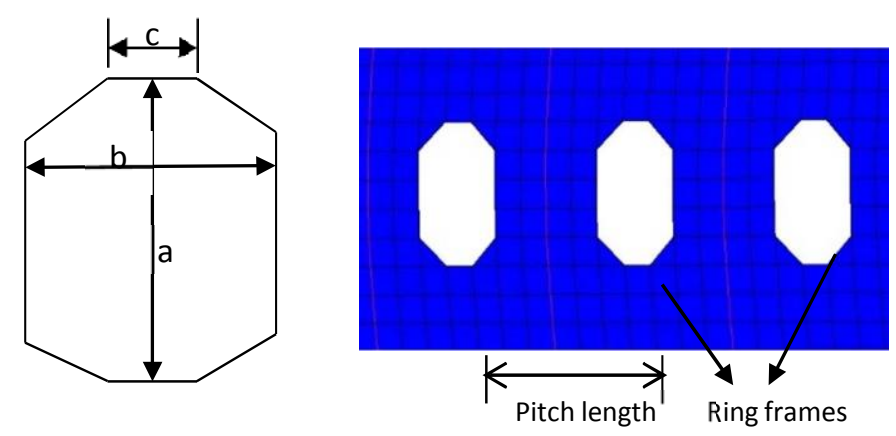

Figure 11 Pitch length and window position in the fuselage section and geometry of cut-outs: $a=420.35 \mathrm{~mm}, b=250.46 \mathrm{~mm}, c=83.46 \mathrm{~mm}$

\section{Boundary conditions}

Bending, shear, and torsion loads were applied at the end of the left fuselage section by means of a RBE2 rigid element linking central node and all other free end nodes shown in Figure 12. The functionality of this element is to smear the loads at the central node across the whole cross-section so as to reduce the local loading effect. The opposite end was fixed but can freely expand in the radial direction due to the difference in pressure inside and outside the fuselage.

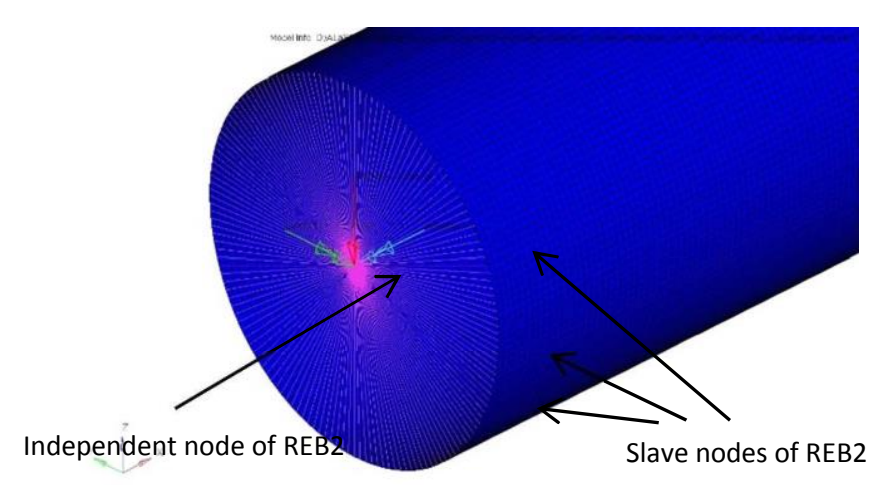

Figure 12 REB2 rigid element 


\section{Lattice fuselage design of a forward-swept wing aircraft}

By applying Eq. (1), the fuselage design by topology optimization was formulated below:

Objective: Minimize the compliance of the fuselage,

Design variables: Artificial material density q for each finite element in the designable area,

Constraints: Volume fraction: $\frac{V_{0}}{V_{n}} \leq 0.3$

where the left end of the fuselage was applied by the loads including torque, bending and shear; the right end was fully fixed except for the radial displacement; structural masses were applied as distributed loads on the whole barrel. To represent the function of the skin for pressurized and load bending fuselage as well as obtain the efficient pattern of reinforcements, a minimum thickness $(0.1 \mathrm{~mm})$ is assigned to the skin to simulate its membrane function, however bending loads are mostly carried by stiffeners, whose arrangements are driven by topology optimization for maximal load-carrying capability. $V_{n}$ was the volume of finite elements involved in each iteration of the optimization process and $V_{0}$ was the maximum volume of the designable structure.

\section{Lattice design of the fuselage section without windows}

Since the Load Case 1 (LC1, downwards loads related) represents the critical driving loads, it should produce the highest corresponding compliance among all the load cases. Hence, loads from LC1 were applied to investigate the efficient pattern of reinforcement on the skin of the fuselage section. Using OptiStruct, the optimal results of the fuselage barrel modelled with structural elements (2D shell and 1D beam) were given in Figure 13. By 2D shell element modelling, the angle of rib-like stiffeners at the mid-surface of the skin parallel to the fuselage axis is measured as approximate 38 degree, which agrees with 40 degree predicted by Central Aerohydrodynamic Institute's (TsAGI). In terms of 1D beam element modelling, a clear pattern of criss-cross stiffeners can also be observed in Figure 13. It is not surprised to identify many horizontal paths of beam elements near the upper and lower extremities of the fuselage cross-section, which will function as the load-carrying backbones. For topology optimization under multi-load cases, the optimal results of the models with 2D shell and 1D beam elements were shown in Figures 14 and 15, respectively.

Since LC1, the critical load case, drives the lattice design of the fuselage, the optimal results from the multi-load case optimization maintain the similarities with the ones from LC1. The differences of the results between them are: 1) More horizontal reinforcements have emerged in a more clear form, and 2) A backbone in Figure 14 is observed at the mid-surface of the skin parallel to the fuselage axis due to the sideways loads (Load case 2) considered in the multi-load case study. This has been also reflected on the result obtained by 1D beam element modelling in Figure 15, which indicates more horizontal paths of beam elements at the rear of the fuselage to bear the larger $z$ direction bending moment as compared with the result in Figure 13. 

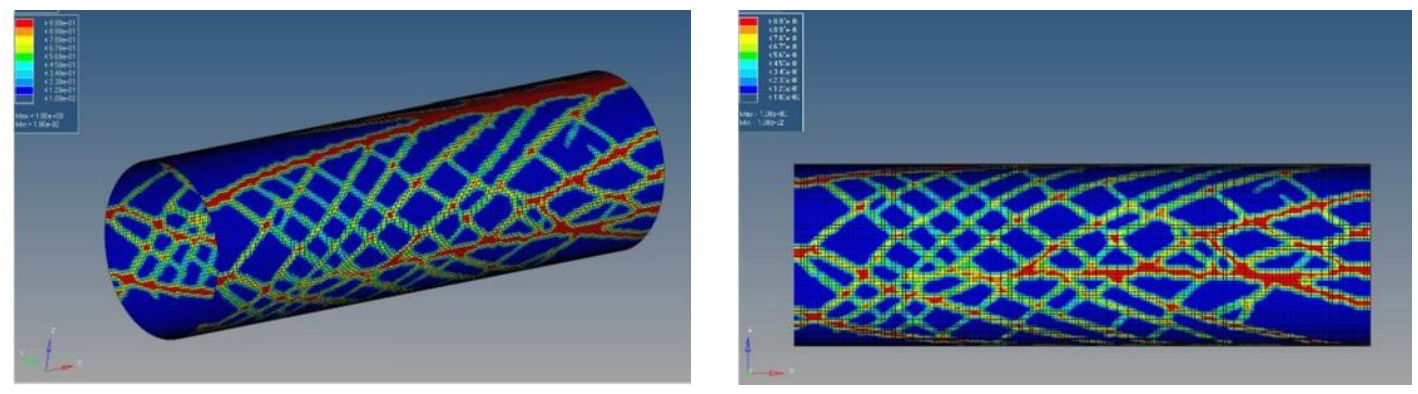

Figure 14 Pattern of optimal reinforcement under multi-load cases with 2D shell element modelling, Iso view (left) and side view (right)

Figure 13 Side view of the optimal reinforcement pattern under LC1:

2D shell (left) and 1D beam (right)

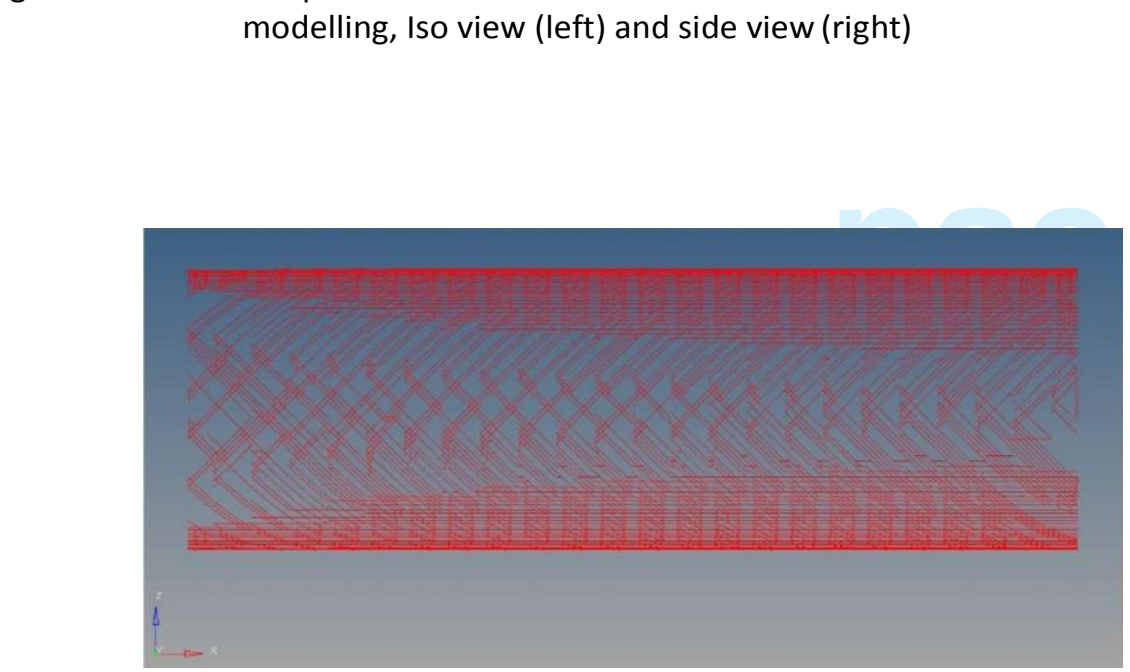

Figure15 Side view of the optimal reinforcement pattern under multi-load cases with 1D beam element modelling 
Lattice design of the fuselage section with windows

In order to investigate the effect of cut-outs on the efficient reinforcement layout of the fuselage, topology optimization of the fuselage section with cut-outs was performed in this section. For the fuselage barrel with the pitch length of $584.2 \mathrm{~mm}$, the shape, the position, and the number of cutouts (22) were described in Figures 10 and 11. Regarding LC1, it is worth noting that clearer formation and higher density of criss-cross stiffeners surrounding the window areas were identified in Figure 16 than those in Figure 13. This can be explained with the more lattice structures required to transfer loads to the backbones in the regions near the windows. For the fuselage model with 2D shell elements, the angle of truss-like stiffeners passing the window locations indicates about 38 degree shown in Figure 16 and agrees with the angle observed in Figure 13. However, the angle of criss-cross stiffeners around the window locations is 45 degree for the fuselage modeled with 1D beam elements. It is because only 0,90 , and 45 degrees are used when modelling the fuselage with $1 \mathrm{D}$ beam elements. This obviously restricts the design space with more constraints as compared to the one for the optimization with 2D shell elements. In the multi-load case study, the higher density of lattice structures around the window locations was formed in Figure 17 than the result shown in Figure 16 and again, the backbone at the mid-surface of the skin parallel to the fuselage axis is observed as well. For the fuselage modelled with 1D beam elements, the optimal patterns of reinforcement (lattice element) on the barrel skin without and with windows under the multi-load case were shown in Figures 15 and 18, respectively. A very distinctive feature which has been presented as a consequence of the topology optimization process can be concluded that the high density for criss-cross stiffeners and horizontal paths of the beam elements can be observed near the rear of the fuselage, then it is gradually reduced along the fuselage axis to the front end due to the smaller bending moments applied. This agrees well with the result from the Michell cantilever study.
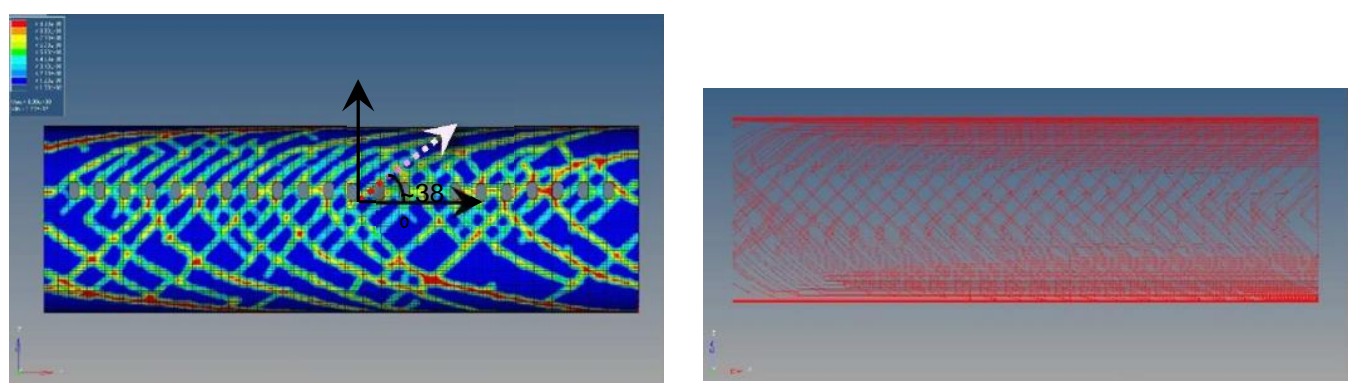

Figure 16 Side view of the optimal reinforcement pattern under LC1:

In use of 2D shell (left) and 1D beam (right) elements to model the fuselage with windows 

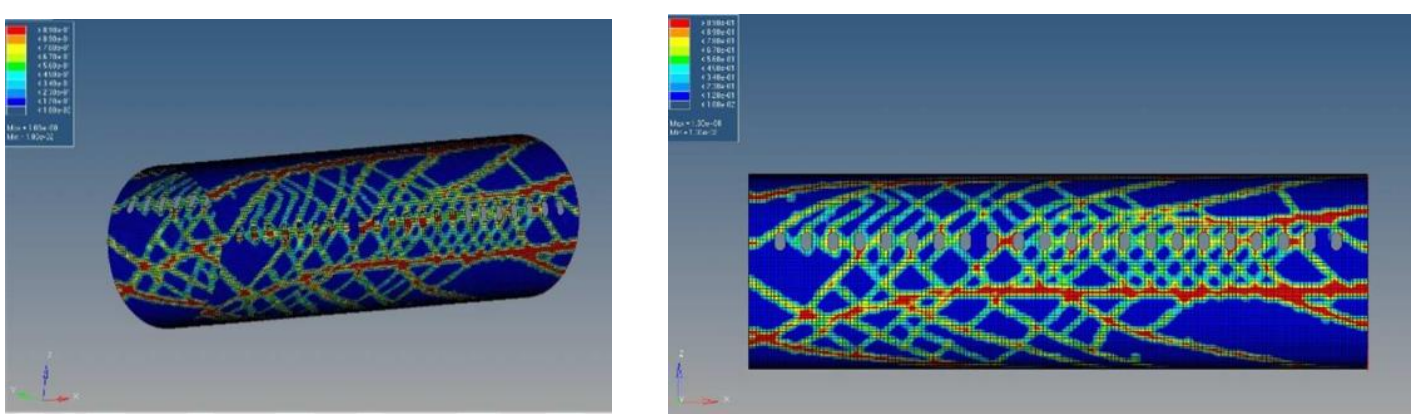

Figure 17 Pattern of optimal reinforcement under multi-load cases in use of 2D shell element to model the fuselage with windows, Iso view (left) and side view (right)

Figure 18 Side view of the optimal reinforcement pattern under multi-load cases in use of $1 \mathrm{D}$ beam element to model the fuselage with windows

\section{Practical design of the lattice fuselage}

Actually, the lattice stiffeners are very complex and expensive to manufacture due to their continual varying sizes in the design process as well as other constraints, for example, buckling constraint. Based on the optimal layouts of the reinforcements in Figures 14-15 and 17-18 for the fuselage without and with cutouts respectively, the ideally representative pattern of varying angle stiffeners can be depicted in Figure 19(a) and its practical design was reflected by CRISM-DLR demonstrator shown in Figure 19(b). Taking into account manufacturing costs of the lattice structures, it is reasonable to simplify these stiffeners with constant angle accordingly, then align them along geodesic lines on the inside and outside of the fuselage skin shown in Figure 20. Another feature of such lattice fuselage is demonstrated by the varying density distribution of the stiffeners along the fuselage axis due to bending loads increased from the front of the fuselage to the rear. Obviously, the lattice fuselage structure in Figure 20 is much easier and less expensive to 
be produced and also beneficial from a structural mechanics point of view due to avoidance of secondary bending of the stiffeners.

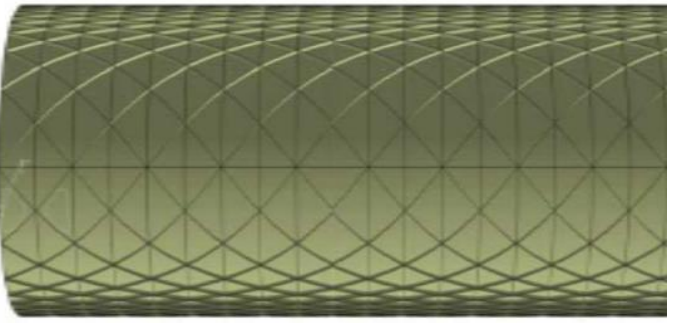

(a)

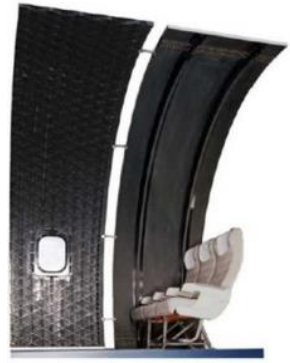

(b)

Figure 19 (a) Fuselage featured by continually varying angle stiffener arrangement;

(b) A full-scale CFRP demonstrator

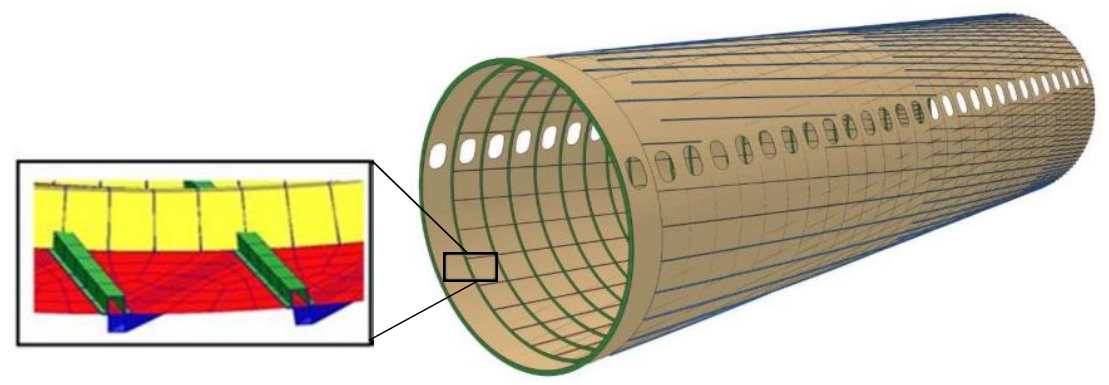

Figure 20 Barrel with constant angled stiffeners and different stiffener density from the front to the rear

\section{Conclusions}

A new lattice fuselage design of a forward-swept wing aircraft was developed in this paper. Topology optimization was performed to determine the conceptual design of a fuselage barrel section modelled with $1 \mathrm{D}$ beam and 2D shell elements, respectively. The topological results revealed the need for horizontal stiffeners to be concentrated near the upper and lower extremities of the fuselage cross section and a lattice pattern of criss-cross stiffeners should be well-placed along along the sides of the fuselage and near the regions of window locations. The slight influence of windows on the optimal reinforcement layout was observed, but the clearer lattice pattern was identified for the fuselage with cut-outs. To obtain clear criss-cross stiffeners, modelling the fuselage with 1D beam elements is suggested, but the more computational time is required due to the larger numbers of elements and nodes as compared to those in the model with 2D shell elements. Since a limited number of angles, for example 0,90 , and 45 degrees, are used to 
model the fuselage with 1D beam elements, the optimal layout of criss-cross stiffeners can only be presented by the given orientations of the beam elements, while the optimization of the fuselage modelled by $2 \mathrm{D}$ shell elements can form more accurate paths for reinforcements due to a larger design space. It is concluded that the optimal designs of the fuselage structures by 1D beam and 2D shell elements have an overall good agreement and this demonstrates the correctness of such a lattice fuselage concept for the design of forward-swept wing aircrafts. This conceptual design of lattice stiffeners was first validated by CRISM-DLR demonstrator, and then, inspired by the optimal designs of stiffeners for the fuselage modelled with 1D beam and 2D shell elements, a lattice barrel with constant angled stiffeners and different stiffener density from the front to the rear is developed by DLR. Finally, using topology optimization as a design tool, the obtained optimal lattice layout of the stiffeners is distinctive to the conventional semi-monocoque fuselage design and also provides valuable insights into the more efficient utilization of composite materials for novel aircraft designs.

\section{Declaration of conflicting interests}

The authors declare that there is no conflict of interest regarding the publication of this paper.

\section{Acknowledgments}

The authors acknowledge the support of the European Commission ( $\operatorname{Dr}$ C. Huehne, DLR) and the Russian government (Dr A. Shanygin, TsAGI) within the Advanced Lattice Structures for Composite Airframes (ALaSCA) research project.

\section{References}

Airframe (2012), Aviation Maintenance Technician Handbook, Vol.1, U.S. Department of Transportation.

ALaSCA (2013), "Advanced Lattice Structures for Composite Airframes”, Project Reference: 265881, Available: http://cordis.europa.eu/project/rcn/97744_en.html.

Altair OptiStruct (2013), V12.0. http://www.altairhyperworks.com/product/OptiStruct

Anand, A., Kapdi, S., M D Jinto, M.D., and Bhuwal, A. (2016), "Light weight structures - application of topology optimization using stress limit as a criteria in formulation", International NAFEMS Conference on Engineering Modeling, Analysis, Simulation and 3D Printing, 29-31 August 2016, Bangalore, India.

Bendsøe. M.P. (1989). "Optimal shape design as a material distribution parameter problem", Struct. Optim., Vol. 1, pp. 193-202.

Bendsøe, M. and Sigmund, O. (2003), Topology Optimization: Theory, Methods and Applications, Springer. 
Daniel, I.M. and Ishai, O. (2005), Engineering Mechanics of Composite Materials, 2nd ed., Oxford University Press.

Deaton, J.D. and Grandhi, R.V. (2014), "A survey of structural and multidisciplinary continuum topology optimization: post 2000", Structural and Multidisciplinary Optimization, Vol. 49, pp.138.

Harzheim, L. and Graf, G. (2005), “A review of optimization of cast parts using topology optimization - Part 1", Structural and Multidisciplinary Optimization, Vol. 30 (6), pp. 491-497.

Herbeck, L., Wilmes, H.R., Kolesnikov, B., and Kleineberg, M. (2003), "Technology and design development for a cfrp fuselage", 25th SAMPE Europe Conference, Paris, France.

James, K.A., Kennedy, G.J., and Martins, J.R.R.A. (2014), “Concurrent aerostructural topology optimization of a wing box", Computers and Structures, Vol. 134, pp. 1-17.

Kolesnikov, B. and Herbeck, L. (2004), “Carbon fiber composite airplane fuselage: concept and analysis", Conference: Merging the Efforts: Russia in European Research Programs on Aeronautics, Berlin, Germany, pp. 1-11.

Krog L., Tucker A., Kemp, M., and Boyd, R. (2004), "Topology optimization of aircraft wing box ribs", In: 10th AIAA/ISSMO multidisciplinary analysis and optimization conference, AIAA Paper: 20044481, AIAA/ISSMO, Albany, USA

Krog, L., Tucker, A., and Rollema, G. (2002), “Application of topology, sizing and shape optimization methods to optimal design of aircraft components", Proc. 3rd Altair UK HyperWorks Users Conference.

Michell A.G.M. (1904), "The limits of economy of material in frame structures", Phil Mag Ser 6, Vol. 8(47), pp.589-597.

Mlejnek, H.P. (1992), "Some aspects of the genesis of structures", Struct. Optim., Vol. 5, pp. 64-69.

Niemann, S., Kolesnikov, B., Lohse-Busch, H., Huehne, C., Querin, Q.M., Toropov, V.V., and Liu, D. (2013), "The use of topology optimisation in the conceptual design of next generation lattice composite aircraft fuselage structures", Aeronautical Journal, Vol.117, pp.1139-1154.

Ostrower, J. (2011), “Boeing to miss 787 performance spec: Albaugh", 15 March 2011. https://www.flightglobal.com/news/articles/boeing-to-miss-787-performance-spec-albaugh354340/

Prager, W. (1974), "A note on discretized Michell structures", Computer Methods in Applied Mechanics and Engineering, Vol. 3(3), pp. 349-355.

Quilter, A. (2004), "Composites in aerospace applications", An IHS White Paper, http://www.aviationpros.com/article/10386441/composites-in-aerospace-applications

Rao, J.S., Kiran, S., Chandra, S., Kamesh, J.V., and Padmanabhan, M.A. (2008), "Topology optimization of aircraft wing", HyperWorks Technology Conference 2008, 31 July-02 August 2008, Bangalore, India.

Rozvany, G.I.N. (1998), “Exact analytical solutions for some popular benchmark problems in topology optimization", Structural and Multidisciplinary Optimization, Vol. 15, pp. 42-48. 
Rozvany, G.I.N., Bendsøe, M.P., and Kirsch, U. (1995), "Layout optimization of structures", Applied Mechanics Reviews, Vol. 48(2), pp. 41-119.

Rozvany, G.I.N., Zhou, M., and Gollub, W. (1993), "Layout optimization by COC methods: analytical solutions", Proc. NATO ASI Series, Vol.231, pp. 77-102.

Russell, H.T., Burley, C.L., and Olson, E. D. (2010), "Hybrid wing body aircraft system noise assessment with propulsion airframe aeroacoustic experiments", 16th AIAA/CEASAeroacoustics Conference, Stockholm, Sweden, 7-9 Jun, AIAA Paper 2010-3913.

Seitz, A., Bijewitz, J., Kaiser, S., and Wortmann, G. (2014), “Conceptual investigation of a propulsive fuselage aircraft layout", Aircraft Engineering and Aerospace Technology: An International Journal, Vol. 86 (6), pp. 464-472.

Seitz, A., Kruse, M., Wunderlich, T., Bold, J., and Heinrich, L. (2011), "LamAiR: Design of a NLF forward swept wing for short and medium range transport application", 29th AIAA Applied Aerodynamics Conference, Honolulu, Hawaii, 27-30 June, AIAA2011-3526.

Shanygin, A., Fomin, V., and Kondakov, I. (2012), "Designing pro-composite aircraft concepts and layouts to maximise potential benefits of high specific strength of CFRP", 28th Congress of the International Council of the Aeronautical Sciences, Brisbane, Australia, 23-28 September, Paper: ICAS 2012-1.7.3.

Sigmund, O. (2001), "A 99 line topology optimization code written in MATLAB", Struct. Multidiscip. Optim., Vol. 21, pp. 120-127.

Vasiliev, V.V., Barynin, V.A., and Rasin, A.F. (2001), "Anisogrid lattice structures - survey of development and application", Composite Structures, Vol. 54, pp.361-370.

Vasiliev, V.V., Barynin, V.A., and Rasin, A.F. (2012), “Anisogrid composite lattice structures development and aerospace applications", Composite Structures, Vol. 94, pp.1117-1127.

Vasiliev, V.V. and Rasin, A.F. (2006), "Anisogrid composite lattice structures for spacecraft and aircraft applications", Composite Structures, Vol. 76, pp.182-189.

Wilmes, H., Kolesnikov, B., Fink, A., and Kindervater, C. (2002), "New design concepts for a cfrp fuselage", Workshop on Final Project of Black Fuselage, Braunschweig, Germany.

Zhou, M., Fleury, R., and Kemp, M. (2010), "Optimization of Composite - Recent Advances and Application", 13th AIAA/ISSMO Multidisciplinary Analysis Optimization Conference, Multidisciplinary Analysis Optimization Conferences, AIAA Paper: 2010-9272, Texas, USA

Zhou, M., Fleury, R., Shyy, Y.K., Thomas, H., and Brennan, J.M. (2002), "Progress in topology optimization with manufacturing constraints", Proc. of the 9th AIAA/ISSMO symposium on multidisciplinary analysis and optimization, Atlanta, pp. 1-8.

Zhou, M., Rozvany, G.I.N. (1991), "The COC algorithm, Part II: topological, geometry and generalized shape optimization", Comp. Meth. Appl. Mech. Engrg., Vol. 89, pp. 197-224.

Zhu, J.H., Zhang, W.H., Xia, L. (2016), "Topology optimization in aircraft and aerospace structures design", Archives of Computational Methods in Engineering, Vol. 23 (4), pp. 595-622. 